UDC 316

Vardgues POGOSYAN

\title{
CHANGE AND VARIABILITY OF PHENOMENA IN COMPLEX SOCIAL SYSTEMS
}

\begin{abstract}
The discourse of chaos theory is used in the description of non-linear processes of social change. Comparing to the mainstream theories of the linear pattern, chaos theory shows significant expansion of the heuristic capabilities in the interpretation of asynchrony and polyvariance of the observed phenomena. A methodological separation of predictability and determinism in the study of socio-dynamics has been carried out. The circumstance that determines the formation of the corresponding attractors is the invariant components of the civilisation matrix of society. The socio-cultural factor, together with the activation of negative feedbacks, is decisive in the problem of absorption by the system of new information, determining the methods and limits of the reception of innovations. In part of the study of the relative homeostatic state of the system in socio-dynamic and for a detailed analysis of the order parameters, the set of which is unique for each specific cultural type, it recommended using as a complement research tool the civilisational approach explaining local specificity.
\end{abstract}

Keywords: social system, social change, invariance, variability, civilisation matrix, order parameter, social-cultural component.

Introduction

The processes of global uniting of humanity taking place in the emerging social reality are objectively determined by the very collectivist nature of man, the development of science and technology, and the intensification of communication. Subjective globalisation gives an ambivalent character to such processes, aimed at forced homogenisation of planetary societies, which leads to an institutional restructuring of a discrete nature, accompanied by an increase in social tension. The heuristic and descriptive limitations of the discourse and theories of the modern linear mainstream social science, containing immanent contradictions and controversial theoretical as- sumptions, result in failure to fully interpret the new changes, which turns to find a proper methodological instrument for an adequate scientific reflection of social reality.

The objective existence of diverse, historically evolving forms of social formations, the non-identity of the observed phenomena, the variety of options for the purposeful social action and the asynchrony of the processes on a planetary scale imply a polyvariance of the sociohistorical process. The specificity of the local, in turn, makes it possible to talk about the phenomenon of civilisation, defined as an established historically unique system with the properties of self-development and self-regulation. The central premise of the analysis of socio-dynamics is that 
the causes of social change lie in the nature of social dispensation. The focus is on the analysis of the conditions and mechanisms of the social order, its supporting elements, the changes occurring in it, the classification of the types of such an order.

\section{Objectives and Methodology}

The object of the study is the methodological approaches existing in sociological science as fundamental research orientations and methods for determining the object of study. Of interest are the heuristic and descriptive possibilities of such theoretical constructs of both linear and civilisational patterns, in terms of the ability of the latter to serve as adequate research tools in the study of social systems and interpretation changes occurring in them. Paradigm consistency of specific methodological approach is considered through the prism of the attitude to the phenomenon of social changes, and the criterion of the adequacy of the approach determines its compliance with the actual functioning of social systems using the scientific potential of the theory to ensure their stability and safety. An own attempt is presented to identify the discursive possibilities of chaos theory concerning the macrosociological analysis of social changes in general and the phenomenon of social modernisation as a variety of such changes within the framework of a civilisational approach.

Since the question of the order and relative homeostasis of the system implies emerging perturbations and ongoing changes, a critical review of the interpretations of such changes and phenomena in frames of traditional approaches has been carried out. With all the pluralism of modern approaches, polyparadigmality in the interpretations of the socio-historical process, the civ- ilisation approach based on the principle of selfsufficiency of local development and the uniqueness of the forms of specific societies has more integrity, consistency and adequacy. Giving preference to the civilisational approach, which connects the historical stages of cultural systems with their ontological discreteness and valuenormative uniqueness, it should be noted that the socio-cultural dominant in the understanding of historical dynamics is a prerogative in the study of civilisations, but it does not overlap other discoveries of this paradigm: dialectical coupling and mediation of "society" and "culture", which is sometimes ignored in modern institutional reconstructing, but, in fact, acts as a program for understanding the dynamics of local sociocultural worlds.

Results and Discussion

\section{Interpretation of changes in theories of linear and civilisational patterns}

The formulation of the question in the social theory developed along with the transformation of the analysis of these phenomena into the starting path of understanding the mechanisms of social order, the conditions of functioning and the prerequisites for changing this order in general and its varieties in particular. This means that social disorder does not differ in nature and nature from order and is not primary to it, but results from the same order - characterised by a different set and correlation of conditions and elements. Thus, it is assumed that social disorganisation can be a backbone factor establishing social order, and can serve as a starting point in the study of social change. Moving in this direction, the sociological analysis focuses on the tendency of social systems to transform, and this kind of tendency is defined as the central aspect 
of the social order, and not as an external or random event.

In an attempt to explain the processes of maintaining institutional order, an analysis of social change is involved. Two main directions can be distinguished, in accordance with which studies of social transformations are carried out: linear and civilisational patterns of development.

The linear approach consists in a onedimensional consistent-progressive development of humankind; within which it is believed that social changes occur either through evolution or through revolution.

In the first case, social changes take place step by step; they are progressive; societies change from simple to complex differentiated ones, from military-agrarian to industrial-urban (A. Comte, G. Spenser, E. Durkheim). Functionalism, as a methodology of sociology, in a certain way preserves evolutionary traditions ( $\mathrm{T}$. Parsons, L. Cozer, R. Darendorf, R. Bendix, R. Collins, K. Levy-Strauss). Revolutionary theories, however, prioritise the clash of political interests of various classes, and the fundamental social changes themselves are the result of their conflict, the result of the struggle is the emergence of fundamentally new social systems $(\mathrm{K}$. Marx, I. Wallerstein, S. Amin, P. Bode).

Explanations of the functioning of a social system within the framework of all theories of a linear pattern, including modified postclassical, goes back to structural-functional sociology. According to the structural-functional approach developed by T. Parsons, the main reasons for changes in social systems can be imbalance trends, which are always present in the relationship between the social system and its environment; the tension that exists between the normative and structural elements of any social system (Parsons, 1966). The system is homeostatic, equilibrium or in a state of relative stability, stable or in relative equilibrium, if, as a result of interaction with the external environment, its immanent properties remain unchanged (Parsons, 1964). He also postulates the need for the highest degree of autonomy of society among other social systems that can implement different social formations in different historical periods.

The methodological weakness of the structural-functional approach - the neglect of the significance of internal conflicts in the functioning of social systems, as well as the relationship between such conflicts and social changes - was identified and criticised by R. Bendix, S. Eisenstadt, R. Darendorf. Nevertheless, even critics of the homeostatic orientation of structural functionalism in creating their theoretical interpretations of social change with a robust anti-systemic bias, but again within the framework of a linear approach, cannot explain the emerging tendencies towards system formation.

The conflict approach, both in its functionalist version proposed by L. Cozer, and in the structuralist version of R. Darendorf (1990), in the writings of R. Bendix and, later, R. Collins, emphasises first of all that the primary source of changes in society is the conflict between groups, defending their material or ideal interests. Thus, R. Bendix built his criticism of structural functionalism and the systems approach as a whole on the fact that modernisation theory is a continuation of evolutionist theories, noting the extraordinary level of abstraction and the failure to explain the reasons for the ongoing historical processes. R. Bendix rejects the idea that the modernisation process is stepwise-staged and mandatory for all societies, and in each country had specific features related to the historical conditions of the formation of this society. The object of criticism in the works of R. Bendix (1967) 
is not only functionalism. Critically analysing historical materialism, R. Bendix disputes the decisive role of the economic imperative in the formation of ideas, and, relying on the cultural factors identified by M. Weber, insists on the importance of their impact in socio-economic development. However, even the conflicting approach with its strong anti-systemic bias fails to explain the emerging trends in system formation. Neglecting the systemic qualities of social entities, often denying the existence of such qualities, this theory is unable to establish the relative importance of various conflicts for the creation of changes and to assess the impact of conflicts on the direction of changes.

With an emphasis on the role of organic contradictions in the transformation of cultural and social models and orders, a central thesis in the symbolic-structuralist approach of C. LevyStrauss is connected. Under this approach, the symbolic transformations that occur when resolving deep-seated contradictions, similar to those between culture and nature, also explain the transition of social orders (for example, the transition from totemic society to caste society). The weak point in the argumentation of symbolic structuralists is the inability to determine the nature of the institutional mechanisms through which the symbolist characteristics of human activity affect institutional life.

The cultural-centric approach to the study of changes, used by S. Eisenstadt (1987), develops in essence despite the main provisions of the structural-functional school associated with the name of T. Parsons. Of particular importance in it is given to the internal contradictions inherent in each of the systems, the degree of emphasis on institutionalisation and symbolic components, the role of elites, and the ratio of internal and external factors. Taking the opposition of the Par- son theory (particularism - universalism) as ideal extremes, S. Eisenstadt introduced a wide range of variable factors and conditions, which removes the classification of the "stages" of the universal transition process, social changes and reveals other types and variants of social structure and dynamics.

The civilisational pattern suggests a qualitatively different reading of the world history of mankind and social transformations (Danilevskii, 2013; Weber, 1978; Spengler, 2006; Toynbee, 1972). Within its framework, social changes (transformations) are considered the norm of the system and the source of its dynamics, but the absolutised social changes have the effect of disrupting existing social relations, leading society as a system into a state of disintegration (Sorokin, 1970).

According to P. Sorokin (1975), social and value polarisation, the weakening of integrative norms and the increase in the level of social deviation are the inevitable consequences of transformational processes, caused by wars, revolutions, social disturbances. In these cases, social change is chaotic, unpredictable and uncontrollable by nature. Nevertheless, social changes can also be organised when they are initiated by the government and its leaders and approved by the majority of citizens. In our opinion, overtaking modernisation, pursuing the goal of a qualitative change in some characteristics of an established system can be attributed to this type of social change. Anyway, in any case, the process of sociocultural changes violates the existing system of relations and causes society to enter a period of disintegration, which, depending on the specifics of transformation processes, may be quick or long, accompanied by social conflicts, or, on the contrary, relatively calm. Such an approach to the macro-sociological analysis of social 
change entirely correlates with the discursive and heuristic possibilities of chaos theory.

\section{Interpretation of changes}

in the theory of chaos

The prospect of using nontrivial approaches to the study of dynamic instability revealed by I. Prigogine (1990) and H. Haken (1983) led to the emergence in the focus of researchers the complex self-organising systems characterised by randomness and limited predictability. Here, it is fundamentally essential to distinguish between determinism and predictability. We insist on the inapplicability of the indeterminism and absolute relativity offered by provisions of Postmodern, which are levelling down causal relationships, negating the cognitive and prognostic functions of science, refuting the postulate "Wisdom is knowledge of principles and causes". Any process takes place in a particular external environment and temporal-spatial continuum is not spontaneous and due to the previous state. The world is not teleological but filled with implications and consequences, its unpredictability is due to the multiplicity of options and variants, but that multiplicity of possible variants is not unlimited. We suggest that the invariant components of the civilisation matrix of each specific society impose such limits, and also form the system-proper attractors.

The multiplicity of options gives the opportunity for polyvariancy phenomena. For example, two systems in which the same laws operate will at a certain point in time be in a not absolutely identical, but relatively similar state, but after a relatively short period, they will become very different in their state. Here there is a phenomenon of aberration, or otherwise, a violation of homo-centricity in relation to the ideal state. The theory of aberration, which came from phys- ics, is applicable in the social sciences and humanities, in particular, one of its propositions, when factors acting in one system are not acted in another system. This theoretical position nullifies attempts at non-constructive forced social engineering (going against constructive, based on endogenous social creativity) to universalise all societies, justifies the likelihood of social laws, explaining the existing diversity of societies and various ways of their development. In the light of the variability of the observed phenomena, the attempts to standardise and synchronise the social processes taking place in various societies appear illogical.

The development paths of self-organising systems are characterised by a certain number of degrees of freedom, which, in turn, are defined by order parameters. But the order parameters are unique for each society, arising historically as initially found survival algorithms in specific climatic and geographical conditions and the existing geopolitical environment and subsequently transforming into invariant elements of a civilisation matrix, causing cognitive and behavioural stereotypes of representatives of a particular cultural-historical type.

Any level of being is a structure distant from equilibrium, which exists due to the dispersion of matter, energy and information. However, these dissipative structures exist stably, which actualises the issue of maintaining order. The presence of direct and feedback plays an essential role in maintaining order, self-organisation of the system, determining its contours. The control of the dynamic system is corrected by circular feedback signalling the achieved adaptive result.

Positive feedback relationships are formed between the system and the external environment. In the context of the subject matter declared by us, such relations can be characterised 
by the consequences of pioneering, primary modernisation, associated with a fundamental discovery aimed at increasing the possibility of environmental transformation, which contributes, in turn, to expanding the ecological niche of society.

The main type of feedback to maintain dynamic homeostasis of the system is negative feedback. Negative feedback is responsible for self-organisation and self-regulation of the system, performs adaptive functions, restoring the regular operation of the system after internal disturbances and external causal influences. In such a context, one can trace the connection of this theory of chaos with the catch-up, secondary modernisation, as an adaptive property of the system. Violation of the mechanisms of this type of communication leads to a decrease in the adaptive properties of the system, the amount of information received, left without a corresponding response, increases, the degree of system perturbation increases, which, in our opinion, leads to disastrous social consequences: delays in social development, technological lag, the result is a loss in a war, a revolution, a humanitarian catastrophe.

The crucial role in open systems belongs to fluctuations, oscillations, deviations inherent in the dynamics of the system. Substantial fluctuation deviations exceeding the possible amplitude of the inherent mean values of the parameters can destroy the system. Here we see the strictest need for a balanced approach to institutional reorganisation in social management: the destruction of social institutions acting as regulators without the creation of a social regulator that entirely replaces the previous one is fraught with disastrous consequences. As well as ignoring the fluctuations of several parameters in social management (a sharp increase in unemployment, a decrease in food self-sufficiency, etc.) can trigger negative scenarios.

Deviations in the system caused by disturbances, fluctuations of the communicative field under the influence of external environmental factors are ordered as a result of the action of correlation social interdependencies. In this stream, order parameters and subordinate structures are born, reorganising the elements in a new way. Communication ensures the stability of society, because these procedures (methods of transmission, manners of expression, etc.) act as parameters of order, introducing necessary restrictions (restrictions are the essence of social order). Everything that acts restrictively and thereby, eliminating the uncertainty of the possible, provides for public order, can be considered as a parameter of the order. However, different order parameters act at different levels, and in terms of the self-organisation of society, it is the intra-communication parameters that are most fundamental and at the micro level the systems act as a system-forming mechanism.

The historically established societies are not identical and differ, including socio-cultural bases, with the peculiarity of co-evolutionary selforganisation and adaptive-adaptive influence on the environment, and the order parameters are tied to a particular society, that is, they are not universal. The theory of chaos describes the periods of relative homeostasis in the dynamics of the functioning of systems true, but quite generally and schematically, without specifying and highlighting those elements that support integrative be a base system. Thus, the consideration of elements which support systems integrity requires more detailed study involving additional methodological tools, such as Path Dependence concept, civilisation matrix theory, trans-historical structures, etc. 
Another critical point in the theory of chaos is associated with the passage of a system of points of choice, bifurcation when several alternatives for further movement are placed in front of the system. During this period, the instability of the system, fluctuation fluctuations increase, the role of attractors and random factors arise. We suppose that the choice of the scenario of further evolution, in other words, the way out of the current situation, applied to human society, is carried out with the help of the socio-cultural component of the social system. If necessary, an adequate response, if the adaptive property of the system is involved, the latter can leave the bifurcation state of the modified, absorbing and assimilating from the environment part of the acting information or energy. This actualises the "compatibility principle", i.e. compatibility of a single element with all other elements of the system in which it belongs. This seems to us to be very important since the condition for nondestructive interaction during modernisation borrowing between the innovation introduced and the object being reformed is their relative compatibility. Otherwise, the new innovation will be rejected. Moreover, in the continuation of thoughts about attractors: innovation reception, which in itself destabilises a system, own field of information, is not done at leisure and the whim of voluntarist reformers, but such absorption is a forced, adaptive measure that takes the system out of the crisis point.

The idea of the selectivity and contingency of such a choice correlates with this position. Not every opportunity is actualised and turns into reality. Only that of the originally equally probable possibilities is realised, which concerning the conditions that have developed at the given moment and in this place becomes necessary. In this sense, only real possibilities are realised by chance. There is always only a certain range of ways of social development, and this range is limited by the invariance of the elements of the civilisation matrix. The unique sociocultural component of a specific society determines the amount of absorption of new information, ways of its use, or, as noted above, its complete rejection (Pogosyan, 2008).

Maintaining the relative stability of the system, its homeostatic functioning with simultaneous use of adaptive properties is based on receiving feedback signals and subsequent adjustment to the initial state by the executive mechanisms. The main question of the theory of self-organisation remains the problem of identifying patterns that govern the functioning of systems. Such a question is organically connected with a specific object of social knowledge, the study of it as integrity, and integrity as the ultimate multitude, an aggregate of specific societies that actually coexisted in historical space.

The same vision is preserved in the $\mathrm{K}$. Jaspers' (1953) covariant model of history: simultaneous social changes are sometimes fixed in the independent development of many societies. Balancing the extremes of the world-system analysis of I. Wallerstein (2004), who reduced national societies to the emanations of the world system, the world-integrity could be presented as a combination of differing civilisations. $\mathrm{R}$. Bendix (1973) noted the ability to preserve in every society historically established social structures, which in many cases turn out to be extremely stable and difficult to destroy. This idea is adjoined by the approach of N. Luhmann (1986, 2012), who considers existed social systems as auto-poietic (self-replicated). 


\section{Conclusion}

Consideration of the processes of selforganisation within the framework of the theory of chaos in the study of the objective world allowed to more fully include in the field of view human activity. Chaos theory, focusing on instability, the non-linearity of world processes, considers society as a complex non-linear, open system that has a wide range of possible alternative paths of development due to a particular environment. Any social subject immanent with respect to the social system only connects to the process of social self-organisation, which introduces a specific distortion in the social process, but does not entirely suppress it.

The definite fate of the spontaneity, chaos, internal uncertainty of the social environment is a constructive factor, contributing to the natural construction of a social structure that is dynamically developing. The constant diversity of elements, the controversial range of individual and group interests and actions, potentially including the forms of adaptation to different variants of the future, ensures the flexibility of the system, the possibility of its quick response and adaptation to external conditions that change and modernisation, in this case, acts as an adaptive property of system, which responses by that way to effects of environment.

The theory of chaos concerning social reality is a methodological tool of knowledge with a vast heuristic potential and significant descriptive possibilities of discourse, which allows you to adequately investigate and interpret the state of the object in bifurcation, entropy, fluctuations. Regarding the description of the intervals of stable states, the relative dynamic homeostasis of the system, the descriptive possibilities of chaos theory indicate the importance of feedback ac- tions in these relatively stable states of social systems and mention order parameters. Nevertheless, social normative and value regulators are different in every society, and the set of order parameters is unique in each specific case (Pogosyan, 2018). This circumstance requires the conjugation of research capabilities of the theory of chaos with the theories of civilisation pattern, tracing the stability of institutional structures, actualising the study of the problem of sociocultural codes, genetic bases of formation (civilisation matrices) of local societies and regional civilisations, mechanisms to ensure the self-sufficiency of specific types of individual social organisms, their resistance to modifications and deformations due to internal crises and from exogenous destructive influence.

\section{REFERENCES}

Bendix, R. (1967). Tradition and Modernity Reconsidered. Comparative Studies in Society and History, 9(3), 292-346.

Bendix, R. (1973). State and Society: A Reader in Comparative Political Sociology. Berkeley: University of California Press.

Danilevskii, N. (2013). Russia and Europe: The Slavic World's Political and Cultural Relations with the Germanic-Roman West. Bloomington: Slavica Publishers, Indiana University.

Darendorf, R. (1990). The Modern Social Conflict. An Essay on the Politics of Liberty. Berkeley: University of California Press.

Eisenstadt, S. (1987). Macro-Sociology and Sociological Theory - Some New Directions. Contemporary Sociology, 16(2), 602-609. 
Haken, H. (1983). Synergetics, an Introduction: Nonequilibrium Phase Transitions and Self-Organisation in Physics, Chemistry, and Biology. ( $3^{\text {rd }}$ rev. enl. ed.). New York: Springer-Verlag.

Jaspers, K. (1953). The Origin and Goal of History. New Haven, CT: Yale University Press.

Luhmann, N. (1986). The Autopoiesis of Social Systems. London: Sociocybernetic Paradoxes. London: SAGE Publications.

Luhmann, N. (2012). Theory of Society. (Vol. 1.). Stanford, CA: Stanford University Press.

Parsons, T. (1966). The Structure of Social Action: A Study in Social Theory with Special Reference to a Group of Recent European Writers. New York, London: The Free Press, Collier-Macmillan Limited.

Parsons, T. (1964). A Functional Theory of Change. In Etzioni A. (Ed.), Social Change: Source, Pattern and Consequence (pp. 83-97). New York: Basic Books.

Pogosyan, V. (2008). Social'naya modernizatsiya: strategiya vyzhivaniya (Social Modernisation: Survival Strategy, in Russian). Moscow: Institute of Scientific Information on Social Sciences, Russian Academy of Science.
Pogosyan, V. (2018). Philosophies of Social Behavior Research: Meta-Analytic Review. Wisdom, 11(2), 85-92. https://doi.org/10.24234/wisdom.v11i2. 212.

Prigogine, I. (1990). Time, Dynamics and Chaos: Integrating Poincare's Non-Integrable Systems. Centre for Studies in Statistical Mechanics and Complex Systems at the University of TexasAustin, United States Department of Energy-Office of Energy Research, Commission of the European Communities.

Sorokin, P. (1970). Social and Cultural Dynamics. Boston: Porter Sargent Publishers.

Sorokin, P. (1975). Hunger as a Factor in Human Affairs. Gainesville: University of Florida Press.

Spengler, O. (2006). The Decline of the West. New York: First Vintage Books.

Toynbee, A. (1972). Study of History. Oxford: Oxford University Press, Thames and Hudson Ltd.

Wallerstein, I. (2004). World-Systems Analysis: An Introduction. Durham, NC: Duke University Press.

Weber, M. (1978). Economy and Society: An Outline of Interpretive Sociology. Berkeley: University of California Press. 